\title{
Short and open circuit faults study in the PV system inverter
}

\author{
Mohammed Bouzidi ${ }^{1}$, Abdelkader Harrouz ${ }^{2}$, Tadj Mohammed ${ }^{3}$, Smail Mansouri $^{4}$ \\ ${ }^{1,2}$ Sustainable Development and Computer Science Laboratory, Faculty of Sciences and Technology, University of \\ Ahmed Draia, Adrar, Algeria \\ ${ }^{3}$ Analysis and control of electro-energy and renewable energy systems, University Center of Tamanrasset, Algeria \\ ${ }^{4}$ Energy, Environment and Information Systems Laboratory, Faculty of Sciences and Technology, University of Ahmed \\ Draia, Adrar, Algeria
}

\begin{tabular}{|c|c|}
\hline Article Info & ABSTRACT \\
\hline Article history: & The inverter is the principal part of the photovoltaic (PV) systems that \\
\hline Received Feb 18, 2021 & assures the direct current/alternating current (DC/AC) conversion ( $\mathrm{PV}$ array \\
\hline Revised Apr 6, 2021 & the PV array into AC energy that is directly connected to the electric utility). \\
\hline Accepted Jul 13, 2021 & $\begin{array}{l}\text { In this paper, we present a simple method for detecting faults that occurred } \\
\text { during the operation of the inverter. These types of faults or faults affect the }\end{array}$ \\
\hline Keywords: & $\begin{array}{l}\text { efficiency and cost-effectiveness of the photovoltaic system, especially the } \\
\text { inverter, which is the main component responsible for the conversion. Hence, }\end{array}$ \\
\hline $\mathrm{DC} / \mathrm{DC}$ converter & we have shown first the faults obtained in the case of the short circuit. \\
\hline Inverter failure & $\begin{array}{l}\text { Second, the open circuit failure is studied. The results demonstrate the } \\
\text { efficacy of the proposed method. Good monitoring and detection of faults in }\end{array}$ \\
\hline Open circuit & \\
\hline PV system & faults that appeared in the PV system. The system behavior is tested under \\
\hline Short circuit & variable parameters and conditions using MATLAB/Simulink. \\
\hline
\end{tabular}

This is an open access article under the CC BY-SA license.

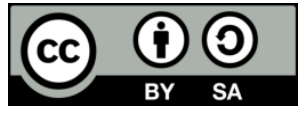

\section{Corresponding Author:}

Bouzidi Mohammed

Sustainable Development and Computer Science Laboratory

Faculty of Sciences and Technology

Department of Electrical Engineering

Ahmed Draia, University of Adrar, Aoulef PB 38 Adrar-Algeria

Email: bouzidi@univ-adrar.edu.dz,mohbouzidi81@yahoo.fr

\section{INTRODUCTION}

Photovoltaic systems have become an environmentally friendly solution to generate electricity in our modern life. They only depend on solar radiation energy, which is a source of energy inspired by nature and considered a source of sustainable energy. Several types of research in the field of solar energy have been elaborated in the last two decades by studying the increasing the efficiency of the PV systems while ensuring the minimum cost of installation [1], [2].

The efficiency is dependent on the components of the PV systems, namely on the efficiency of panels, batteries, and inverters. Also, better monitoring leads to an adequate PV system. However, faults can decrease and even block the well-functioning of the PV system [3]-[7]. A shaded or broken panel, batteries fail and inverter dysfunctions cause losses in the produced energy as well as the economic effect of the PV system. The inverters represent the intermediary device between DC and AC sides. They are used to supply the AC loads. It's based on the commutation between its switchers situated in its arms. This commutation delivers the sinusoidal shape of the output current that feds the AC loads [6], [8], [9]. The switches are the principal element in the conversion operation and any failure in their work breaks the inverter outputs. Hence, faults in the inverter are known as a big problem that causes damages to the functionality of the 
DC/AC converter, AC loads, or other PV system parts. For that, inverter monitoring is an essential task for all PV systems functioning. In [10] they have studied the increasing of the vehicle power train reliability regarding insulated gate bipolar transistor (IGBT) open-circuit failures, 4-wire, and 4-leg pulse width modulation (PWM) inverter topologies investigated and their performances discussed in a vehicle context [4]. In [11] it has been investigated on faults that may occur on the DC link of an inverter fed induction motor and the effect of the capacitor short circuit. It also deals with the effects of the short-circuited capacitor on the freewheeling diode. And, in [12], [13] they have determined the location of the fault, the ratio between DC and AC power. They have developed a software tool to identify different types of faults like fault in a photovoltaic module, fault in a photovoltaic string, fault in an inverter, and a general fault that may include partial shading, PV aging, or maximum power point tracking (MPPT) error. In [5], [14], [15] they have carried out the field measurement for current harmonics. In particular, for a two-stage inverter that assumes the DC-link voltage is constant, the DC-link voltage ripple is identified as the source of a series of odd harmonics. A new periodic time-varying model is proposed by including the DC-link voltage ripple into the conventional current control loop model. In [16]-[18] have focused on the inverter of photovoltaic systems and their characterization. They have obtained a model from a detailed study of main loss processes in smallsize PV inverters in the market. The main advantage of the used method is to obtain a model that comprises two antagonistic features since both are simple, easy to compute and apply, and accurate. However, no one of these papers studied the faults that occurred in the structure of the PV system inverters. Hence, this paper tries to explain the inverter faults effects and gives a general idea of the behavior and the changes in the PV system outputs. It is based on the studying of the PV system functioning in the normal operation and under faults in the inverter. For that, we have proposed in this paper a method that can detect short and open circuit faults in the inverter.

Firstly, we tried to study the short circuit fault in the inverter that is the most known problem in the PV system power conversion. The short circuit fault is dependent on the inverter switch commutation and influences the PV system outputs by decreasing the DC/AC converter parameters which reduce the PV system efficiency. Secondly, we presented the open circuit failure, when one of the inverter switches is opened and stays blocked in its position. This kind of fault affects the PV system continuity and breaks the AC loads supplies.

The rest of this paper is organized is being as. Section 2 shows the PV system device modeling. In Section 3, we present the methodology used in this work to study the failures in the PV system inverter. In Section 4, we have simulated the results obtained from the proposed approach in the case of absence and presence of failure in the PV system inverter. The last section is dedicated to the conclusion and perspective the future work.

\section{METHODOLOGY}

The monitoring of PV system devices is an important part to generate the power produced by these systems. For that, the inverter is presented as an intermediate between the DC and the AC side, and its functioning should be in the correct way to ensure the optimum efficiency. In this regard, a proposed simulation method has been created based on the MATLAB/Simulink environment to study and treat faults in the inverter. In this work, we are interested to study the behavior of the inverter under some specific faults; precisely the short circuit and the open circuit faults. Firstly, the components of the PV system are introduced by relying on the diode photovoltaic cell model. Secondly, a three-phase inverter is modeled where the two types of faults (short circuit and open circuit) to study the behavior are introduced. The proposed structure is shown in Figure 1.

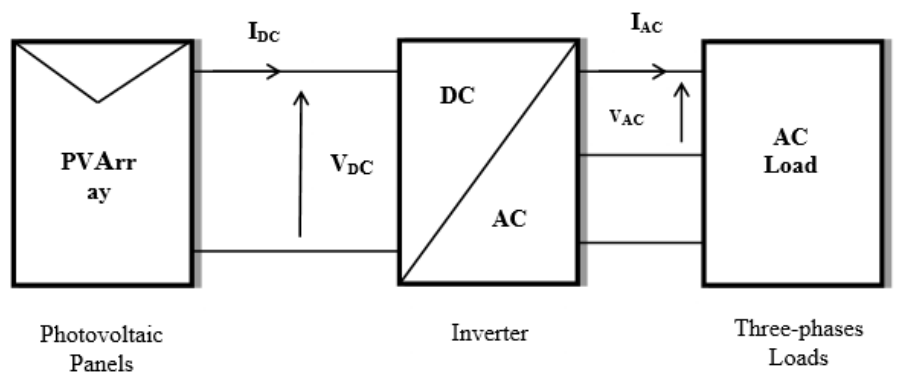

Figure 1. Flowchart of the proposed methodology 


\subsection{Description of $P V$ system devices}

The PV system used in this work consists of eight YL80P-17b 2/3 polycrystalline solar panels. They are connected in parallel and their parameters are summarized in Table 1. The Foshan Tanfon energy technology inverter is used in this study and its characteristics are developed in Table 2.

Table 1. The YL80P-17b 2/3 panel parameters

\begin{tabular}{cc}
\hline Technology & Polycrystalline $\mathrm{Si}$ \\
\hline Peak power & $80 \mathrm{~W}$ \\
Open circuit voltage & $22 \mathrm{~V}$ \\
Short circuit current & $5.04 \mathrm{~A}$ \\
Peak voltage & $17 \mathrm{~V}$ \\
Peak current & $4.71 \mathrm{~A}$ \\
Max system voltage & $50 \mathrm{~V}$ \\
\hline
\end{tabular}

Table 2. Foshan tanfon energy technology inverter

\begin{tabular}{cc}
\multicolumn{2}{c}{ characteristics } \\
\hline Features & Values \\
\hline Output power & $1 \mathrm{KW}-100 \mathrm{KW}$ \\
Nominal voltage & $380 \mathrm{~V} / 415 \mathrm{~V} / 440 \mathrm{~V}$. \\
Maximum efficiency & $>85 \%$ \\
Maximum DC voltage & $384 \mathrm{~V}$ \\
Nominal DC current & $156 \mathrm{~A}$ \\
\hline
\end{tabular}

\subsection{Modeling of PV array}

As presented in a previous paper published by [6], [18], [19], [20], the DC output powers, the output currents, and voltages of the PV array have been calculated using a double diode PV cell model as expressed in (1) [14], [18].

$$
I=I_{p h}-I_{01}\left(\exp \left(\frac{V+R_{S} I}{n_{1} V_{t}}-1\right)\right)-I_{02}\left(\exp \left(\frac{V+R_{S} I}{n_{2} V_{t}}-1\right)\right)-\frac{V+R_{S} I}{R_{s h}}
$$

where Iph is the current generated by the incident light. $\mathrm{I}_{01}, \mathrm{I}_{02}$ is the reverse saturation currents of the diodes $\mathrm{D} 1$ and D2 respectively. Vt is the thermal voltage. $\mathrm{n}_{1}, \mathrm{n}_{2}$ are the ideality factors of diodes $\mathrm{D}_{1}$ and $\mathrm{D}_{2}$. Rs and Rsh are the series and shunt resistance respectively. V and I are the output PV module voltage and current respectively.

\subsection{Modeling of the inverter}

To obtain the efficiency of the DC current and voltage converters into the AC current and voltage, we have modeled this inverter with the standard method given by the next equation. This model expresses the efficiency as a function of the input power $P_{\text {in }}$ [6], [21], [22].

$$
\eta_{D C / A C}=y_{0}+c_{1}\left(1-\exp \left(-c_{2} \times P_{i n}\right)\right)+c_{3}\left(1-\exp \left(-c_{4} \times P_{\text {in }}\right)\right)
$$

The paramertersy $0, \mathrm{c} 1, \mathrm{c} 2, \mathrm{c} 3$, and $\mathrm{c} 4$ are shown in Table 3, these parameters can be obtained using the least square algorithm, minimizing the quadratic function:

$$
S(w)=\sum_{i=1}^{N}\left(P_{i n}-\eta\left(P_{i n}, w\right)\right)^{2}
$$

Table 3. Estimated parameters using least square algorithm [10]

\begin{tabular}{llllll}
\hline Parameters & $\mathrm{y}_{0}$ & $c_{1}$ & $c_{2}$ & $c_{3}$ & $c_{4}$ \\
\hline values & 1.0733 & 1.6817 & 0.0721 & -1.8440 & 0.4069 \\
\hline
\end{tabular}

\section{INVERTER FAULTS STUDY}

The DC/AC converter represents a principle device in the PV system due to its most important work in the production line, when, it ensures to supply the load by the AC power converted from the DC one [23], [24]. The inverter reliability depends on good efficiency, where it cannot be obtained if this converter is not well functioning. Thus, in this study; we have tried to monitor the inverter behavior in the case of good functioning and other cases when we have introduced some faults (we are interested in this approach in the short circuit of one of the inverter arms and the open circuit at the same converter arm) [14], [25], [26], [27].

\subsection{Short circuit fault}

The short circuit is the most current problem in the PV system converters, and it has caused big damages in the photovoltaic installations. However, studying the consequences and the results of this fault provides the knowledge of how this event occurred [22], [28], [29]. The normal functioning of the inverter is started when the first switch S1 of the first arm A1 is closed, which means the current passes throughout S1 
and S4. And the second step is when S3 is closed, then the current will be passed onto S3 and S6. And the last step is when S5 is turned on, which means the current will pass between S5 and S2 as demonstrated in Figure 2 .

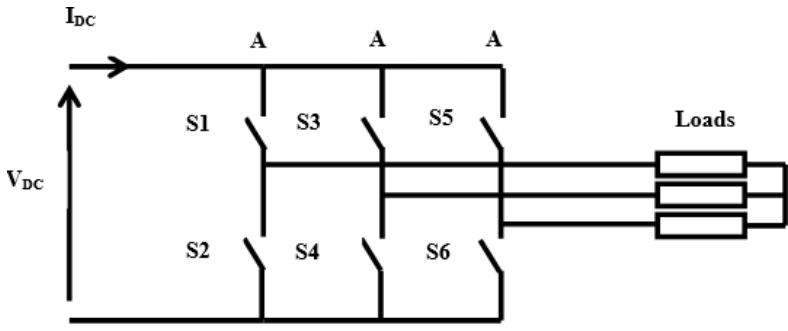

Figure 2. Flowchart of the used inverter in the proposed methodology

\subsection{Open circuit fault}

The open-circuit represents a harmful fault that appears in the DC/AC converter level and it has influenced the PV system efficiency. Hence, the inverter functioning behavior will be changed in this case. This kind of fault depends on the inverter switches commutation and their mode control.

The open-circuit fault is happening in the DC/AC converter when all of its switches are opened. This case could be arriving if one or more switches are opened and stay blocked. The example took in this methodology is when the switch S1 and S4 are opened and the switch S1 stay opened, but the problem is when the switches S5 and S2 become opened. In this state, the open circuit fault is appeared in the switches S1 and S2, and also the switches S5 and S6. This means that the arm A1 and A3 are in case of open-circuit failure. Thus, the PV system efficiency is automatically influenced by the appearance of this in the solar inverter [19], [27], [30].

\section{SIMULATION RESULTS AND DISCUSSION}

The objective of the present work is to study the inverter in normal and under faults functioning. For that, we have used eight YL80P-17b 2/3 polycrystalline solar panels connected in parallel to get more output voltage and they supply the PV system by $550 \mathrm{Wp}$, the PV module parameters are given in Table 1 . The inverter used in this study is a three-phase Foshan Tanfon energy technology and its characteristics are mentioned in Table 2. In all figures, the blue line represents the inverter outputs with normal functioning and the green line show the DC/AC converter outputs with different kinds of failures under study (the short circuit and the open circuit).

\subsection{PV system inverter functioning without failure}

Figure 3 explains the average output power inverter with good operation when this power is in constant value due to a constant solar radiation PV array input and no problem in the inverter commutation switches. Hence, the inverter output power represents the PV system efficiency rate; in this case of normal functioning without faults, the PV system efficiency is in the highest value. In Figure 4 and Figure 5, the curves represent the outputs inverter voltage and current respectively of the first phase of the DC/AC converter used under study. However, both figures are in a sinusoidal form and the current curve is the image of the voltage curve. Thus, we take these curves as a reference to compare them with those of the failure inverter functioning. 


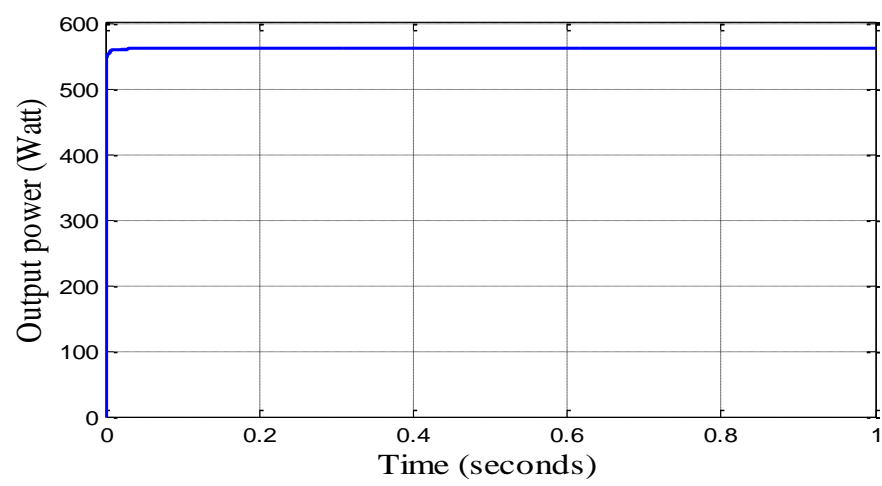

Figure 3. PV system output power with normal functioning (without faults)

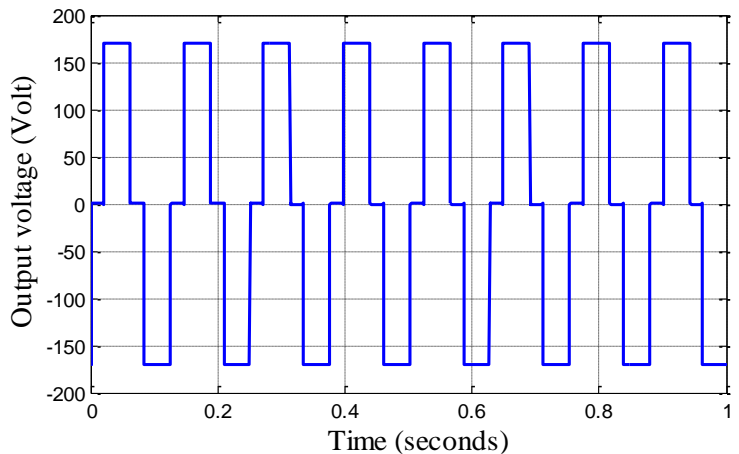

Figure 4. PV system output voltage with normal functioning (without faults)

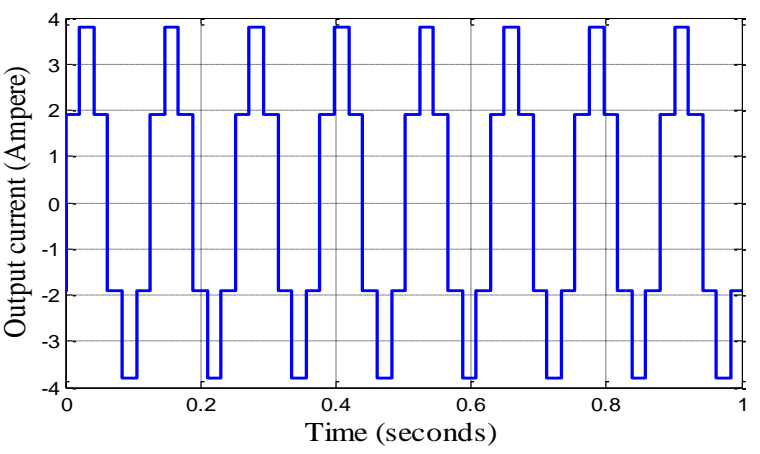

Figure 5. PV system output current with normal functioning (without faults)

\subsection{PV system inverter functioning with short circuit fault:}

Figures 6-8 show the effect of the short circuit in the PV system inverter by the curves of the power, the voltage, and the current respectively. Figure 6 explains a considerable reduction in the output power and no stability in its signal that could damage the device understudy or the load supplied by this power. Figures 7 and 8 are the output voltage and the current of phase 1 of the inverter. However, the current curve is the image of the voltage curve. We observe just the negative part of the current phase in the short circuit case comparing with the normal functioning that means there is a reverse current in the PV system inverter when the arm A1 is short-circuited. For that, it appears just the negative current and voltage form. The three parameters (power, voltage, and current) are linked between them, then one of them changes all of the rest diverge.

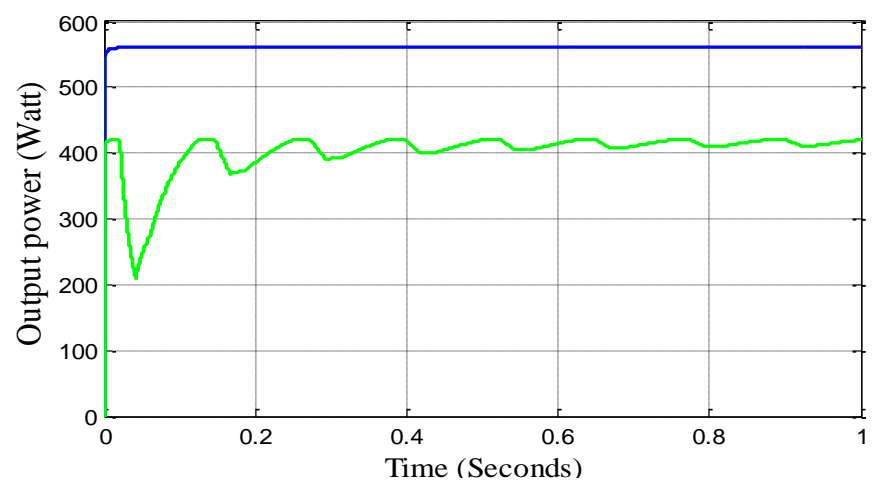

Figure 6. PV system output power under short circuit fault in the inverter arm 


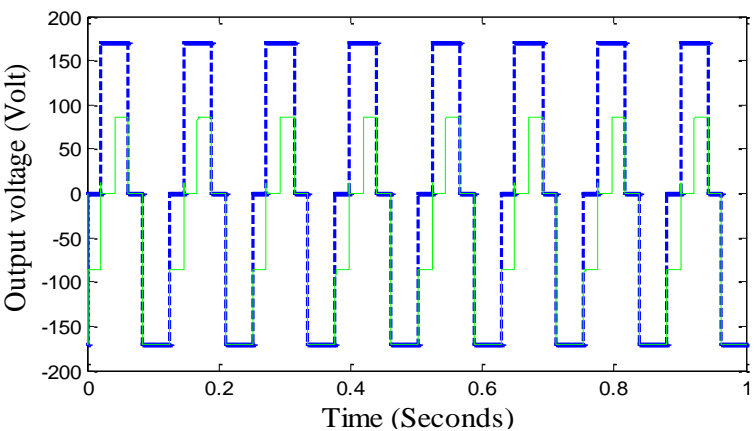

Figure 7. PV system output voltage of the first phase under short circuit fault in the inverter arm

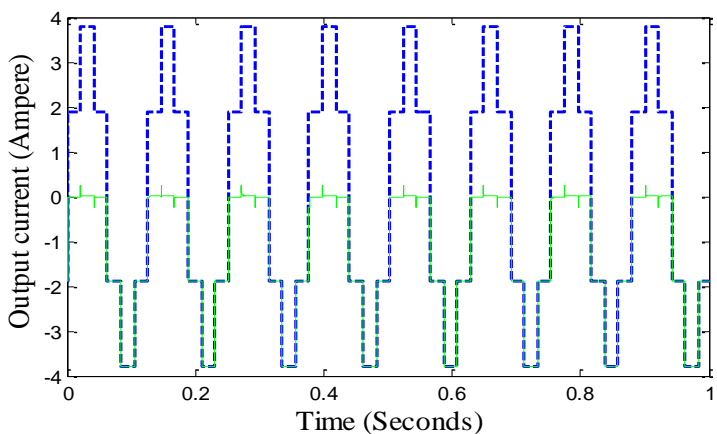

Figure 8. PV system output current of the first phase under short circuit fault in the inverter arm

\subsection{PV system inverter functioning with open-circuit fault}

In this kind of fault, we could notice that in Figure 9 the output power curve drops its values when the open circuit fault is applied and its allure signal still floating. The effect of the open-circuit fault is the decrease of the total PV system efficiency, which causes another deformation in the inverter structure. Figures 10 and 11 explain the output voltage and current respectively of the first phase of the output inverter. The shape of curves shows the profound effect of the open circuit faults in the sinusoidal form of the voltage and the current results. Besides, the open-circuit fault is introduced by opening two switches in the same inverter arm that changes the voltage and the current allures. The current becomes zero at the moment between 0.06 and 0.08 seconds. At this moment, the first open circuit is introduced and it affects the rest of the signal allure. The same thing in the voltage curve, which remains constant at this moment.

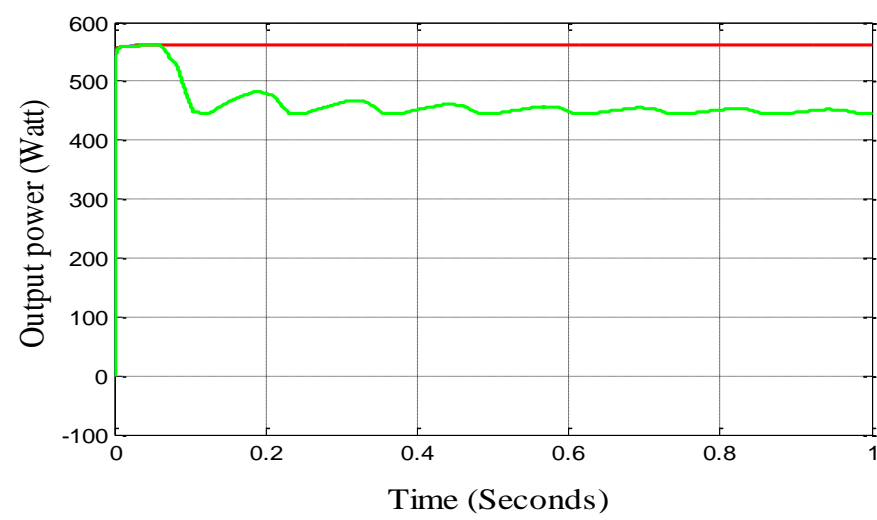

Figure 9. PV system output power under open circuit fault in the inverter arms

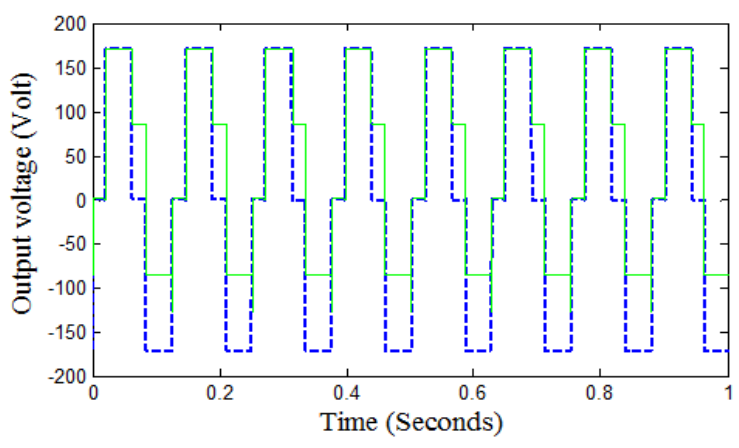

Figure 10. PV system output voltage of the first phase under open circuit fault in the inverter arms

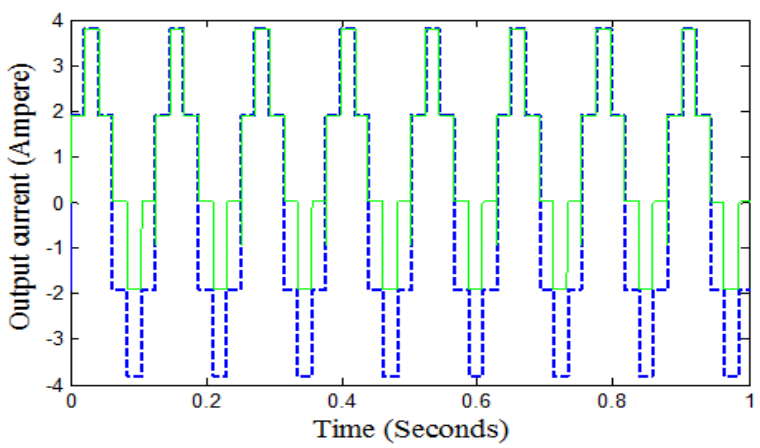

Figure 11. PV system output current of the first phase under open-circuit fault in the inverter arms 


\section{CONCLUSION}

In this paper, we have studied faults that occurred in the inverter especially faults of the short and open circuit of switchers of the inverter. The methodology consists of modeling all the parts of the PV system, namely the panels and the inverter. Then, a description of the inverter with and without faults is presented. The simulation results have shown that a closed blocked switch of one arm of the inverter causes the short circuit fault that leads to a decreasing of the output power with a deformation of the sinusoidal form of the current and voltage outputs. On the other hand, an open circuit fault which occurs when a switch of one arm of the inverter is open and stays blocked in its position causes a zero current value. These faults influence decreasingly the PV system global efficiency. The obtained results showed the efficacy of the proposed method that leads to optimal functioning of the PV system.

\section{ACKNOWLEDGEMENTS}

The authors would like to thank the University of Ahmed Draia of Adrar for the financial aspect of the present work.

\section{REFERENCES}

[1] A. D. Karlis, T. L. Kottas, and Y. S. Brutal, "A novel maximum power point tracking method for PV systemsusing fuzzy cognitive networks (FCN)," Electric Power Systems Research, vol. 77, no. 3-4, pp. 315-327, March 2007, doi: 10.1016/j.epsr.2006.03.008.

[2] R. Rajesh, and M. C Mabel, "Efficiency analysis of a multi-fuzzy logic controller for the determination of operating points in a PV system," Solar Energy, vol. 99, pp. 77-87, January 2014, doi: 10.1016/j.solener.2013.10.036.

[3] K.-H. Chao, S.-H. Ho, and M.-H. Wang, "Modeling and fault diagnosis of a photovoltaic system," Electric Power Systems Research, vol. 78, no. 1, pp. 97-105, January 2008, doi: 10.1016/j.epsr.2006.12.012.

[4] S. Silvestre, M. A. da Silva, A. Chouder, D. Guasch, and E. Karatepe, "New procedure for fault detection in gridconnected PV systems based on the evaluation of current and voltage indicators," Energy Conversion and Management, vol. 86, pp. 241-249, October 2014, doi: 10.1016/j.enconman.2014.05.008.

[5] A. A. Kamel, H. Rezk, N. Shehata, and J. Thomas, "Energy management of a DC microgrid composed of photovoltaic/fuel cell/battery/supercapacitor systems," Batteries, vol. 5, no. 3, p. 63, 2019, doi: 10.3390/batteries5030063.

[6] B. Benabdelkrim, A. Benattilah, and T. Ghaitaoui, "Study of degradation of amorphous PV module performance under different climatic conditions," Algerian Journal of Renewable Energy and Sustainable Development, vol. 1, no. 2, pp. 125-135, 2019, doi: 10.46657/ajresd.2019.1.2.2.

[7] D. Benatiallah, K. Bouchouicha, A. Benatiallah, A. Harrouz, and B. Nasri, "Forecasting of solar radiation using an empirical model," Algerian Journal of Renewable Energy and Sustainable Development, vol. 1, no. 2, pp. 212-219, 2019, doi: 10.46657/ajresd.2019.1.2.11.

[8] A. Coronado-Mendoza and J. A. Domínguez-Navarro, "Dynamic phasors modeling of inverter fed induction generator," Electric Power Systems Research, vol. 107, pp. 68-76, February 2014, doi: 10.1016/j.epsr.2013.09.015.

[9] P. Manohar, and H. S. Chandrasekharaiah, "Artificial commutation for inversion into a weak AC system in a multiterminal HVDC system," Electric Power Systems Research, vol. 19, no. 2, pp. 95-104, August 1990, doi: 10.1016/0378-7796(90)90060-G.

[10] B. Tabbache, M. Benbouzid, A. Kheloui, J.-M. Bourgeot, and A. Mamoune, "An improved fault-tolerant control scheme for PWM inverter-fed induction motor-based EVs," ISA Transactions, vol. 52, no. 6, pp. 862-869, November 2013, doi: 10.1016/j.isatra.2013.07.004.

[11] H. A. Sher, K. E. Addoweesh, and Y. Khan, "Effect of short circuited DC link capacitor of an AC-DC-AC inverter on the performance of induction motor," Journal of King Saud University-Engineering Sciences, vol. 28, no. 2, pp. 199-206, July 2016, doi: 10.1016/j.jksues.2014.03.003.

[12] W. Chine, A. Mellit, A. M. Pavan, and S. A. Kalogirou, "Fault detection method for grid-connected photovoltaic plants," Renewable Energy, vol. 66, pp. 99-110, June 2014, doi: 10.1016/j.renene.2013.11.073.

[13] M. Elabbes and B. Brahim, "Modelling and control of photovoltaic system using the incremental conductance method for maximum power point tracking," Algerian Journal of Renewable Energy and Sustainable Development, vol. 1, no. 2, pp. 191-197, 2019, doi: 10.46657/ajresd.2019.1.2.8.

[14] Y. Dua, D. D. Lu, G. James, and D. J. Cornforth, "Modeling and analysis of current harmonic distortion from grid connected PV inverters under different operating conditions," Solar Energy, vol. 94, pp. 182-194, August 2013, doi: 10.1016/j.solener.2013.05.010.

[15] A. Badoud, "Bond graph model for fault detection of partial shaded PV array considering different module connection schemes and effects of bypass diodes," Algerian Journal of Renewable Energy and Sustainable Development, vol. 1, no. 1, pp. 41-59, 2019.

[16] L. Davila-Gomez, A. Colmenar-Santos, M. Tawfik, and M. Castro-Gil, "An accurate model for simulating energetic behavior of PV grid connected inverters," Simulation Modelling Practice and Theory, vol. 49, pp. 57-72, December 2014, doi: 10.1016/j.simpat.2014.08.001. 
[17] J. Hu, Y. Shan, Y. Xu, and J. M. Guerrero, "A coordinated control of hybrid ac/dc microgrids with PV-windbattery under variable generation and load conditions," International Journal of Electrical Power \& Energy Systems, vol. 104, p. 583-592, January 2019, doi: 10.1016/j.ijepes.2018.07.037.

[18] M. Tadj, K. Benmouiza, and A. Cheknane, "An innovative method based on satellite image analysis to check fault in a PV system lead-acid battery," Simulation Modelling Practice and Theory, vol. 47, pp. 236-247, September 2014, doi: 10.1016/j.simpat.2014.06.010.

[19] F. Attivissimo, F. Adamo, A. Carullo, A. M. L. Lanzolla, F. Spertino, and A. Vallan, "On the performance of the double-diode model in estimating the maximum power point for different photovoltaic technologies," Measurement, vol. 46, no. 9, pp. 3549-3559, November 2013, doi: 10.1016/j.measurement.2013.06.032.

[20] J. Kumar, A. Agarwal, and V. Agarwal, "A review on overall control of DC microgrids," Journal of Energy Storage, vol. 21, pp. 113-138, February 2019, doi: 10.1016/j.est.2018.11.013.

[21] D. Ravi, B. M. Reddy, S. L. Shimi, and P. Samuel, "Bidirectional de to de converters: an overview of various topologies, switching schemes and control techniques," International Journal of Engineering and Technology, vol. 7, no 4.5, pp. 360-365, 2018.

[22] A. I. Bratcu, I. Munteanu, S. Bacha, D. Picault, and B. Raison, "Cascaded DC-DC converter photovoltaic systems: power optimization issues," IEEE Transactions on Industrial Electronics, vol. 58, no. 2, pp. 403-411, Feb. 2011, doi: 10.1109/TIE.2010.2043041.

[23] A. Haddou, N.-E. Tariba, N. ikken, A. Bouknadel, H. EL Omari, and H. EL Omari, "Comparative study of new MPPT control approaches for a photovoltaic system," International Journal of Power Electronics and Drive System (IJPEDS), vol. 11, no. 1, pp. 251-261, March 2020, doi: 10.11591/ijpeds.v11.i1.pp251-261.

[24] A. Khatibi, F. R. Astaraei, and M. H. Ahmadi, "Generation and combination of the solar cells: A current model review”, Energy Science \&Engineering, vol. 7, no. 2, pp. 305-322, March 2019, doi: 10.1002/ese3.292.

[25] G. Sureshkumaar, N. Kannan, and S. Thomas, "MATLAB/SIMULINK based simulations of KY converter for PV panels powered led lighting system," International Journal of Power Electronics and Drive System (IJPEDS), vol. 10, no. 4, pp. 1885-1893, December 2019, doi: 10.11591/ijpeds.v10.i4.1885-1893.

[26] M. R. Sourov, U. T. Ahmed, and M. G. Rabbani, "A high-performance maximum powerpoint tracker for photovoltaic power system using DC-DC boost converter," IOSR Journal of Engineering, vol. 2, no. 12, pp 12-20, 2012.

[27] G. Notton, V. Lazarov, and L. Stoyanov, "Optimal sizing of a grid-connected PV system for various PV module technologiesand inclinations, inverter efficiency characteristics, and locations," Renewable Energy, vol. 35, no. 2, pp. 541-554, February 2010, doi: 10.1016/j.renene.2009.07.013.

[28] H. Sahraoui, L. Chrifi-Alaoui, S. Drid, and P. Bussy, "Second order sliding mode control of DC-DC converter used in the photovoltaic systemaccording an adaptive MPPT," International Journal of Renewable Energy Research (IJRER), vol. 6, no. 2, pp. 375-383, 2016.

[29] G. Sureshkumaar, N. Kannan, S. Thomas, and S. P. Karthikeyan, "MATLAB/Simulink simulations based modified sepicDC to DC converter for renewable energy applications," Journal of Advanced Research in Dynamical and ControlSystems, vol. 11, no. 4, pp. 285-295, 2019.

[30] J. Moreno-Valenzuela, and O. García-Alarcón, "On control of a boost DC-DC power converter under constrained input," Complexity, vol. 2017, 2017, doi: 10.1155/2017/4143901. 